\title{
Impact of pathological tumor stage for salvage radiotherapy after radical prostatectomy in patients with prostate-specific antigen $<1.0 \mathrm{ng} / \mathrm{ml}$
}

Rei Umezawa*, Hisanori Ariga, Yoshihiro Ogawa, Keiichi Jingu, Haruo Matsushita, Ken Takeda, Keisuke Fujimoto, Toru Sakayauchi, Toshiyuki Sugawara, Masaki Kubozono, Kakutaro Narazaki, Eiji Shimizu, Yoshihiro Takai and Shogo Yamada

\begin{abstract}
Background: To evaluate prognostic factors in salvage radiotherapy (RT) for patients with pre-RT prostate-specific antigen $(P S A)<1.0 \mathrm{ng} / \mathrm{ml}$.

Methods: Between January 2000 and December 2009, 102 patients underwent salvage RT for biochemical failure after radical prostatectomy (RP). Re-failure of PSA after salvage RT was defined as a serum PSA value of $0.2 \mathrm{ng} / \mathrm{ml}$ or more above the postradiotherapy nadir followed by another higher value, a continued rise in serum PSA despite salvage RT, or initiation of systemic therapy after completion of salvage RT. Biochemical relapse-free survival (bRFS) was estimated using the Kaplan-Meier method. Multivariate analysis was performed using the Cox proportional hazards regression model.

Results: The median follow-up period was 44 months (range, 11-103 months). Forty-three patients experienced PSA re-failure after salvage RT. The 4-year bRFS was 50.9\% (95\% confidence interval [95\% Cl]: 39.4-62.5\%). In the log-rank test, pT3-4 ( $p<0.001)$ and preoperative PSA $(p=0.037)$ were selected as significant factors. In multivariate analysis, only pT3-4 was a prognostic factor (hazard ratio: 3.512 [95\% Cl: 1.535-8.037], $p=0.001$ ). The 4-year bRFS rates for pT1-2 and pT3-4 were 79.2\% (95\% Cl: 66.0-92.3\%) and 31.7\% (95\% Cl: 17.0-46.4\%), respectively.

Conclusions: In patients who have received salvage RT after RP with PSA $<1.0 \mathrm{ng} / \mathrm{ml}$, pT stage and preoperative PSA were prognostic factors of bRFS. In particular, pT3-4 had a high risk for biochemical recurrence after salvage RT.
\end{abstract}

Keywords: Prostate cancer, Radiotherapy, Radical Prostatectomy, PSA, Pathological tumor stage

\section{Background}

Radical prostatectomy (RP) is one of the curative treatments for prostate cancer. However, biochemical recurrence after radical prostatectomy occurs in approximately $15 \%$ to $40 \%$ of patients within 5 years [1,2]. Approximately one third of patients with biochemical recurrence will have distant metastases, and the median actuarial period to development of metastases following prostate-specific antigen (PSA) elevation is 8 years [3]. Many studies have demonstrated that salvage radiotherapy (RT) for biochemical recurrence after RP is effective and enables long-term suppression of PSA elevation [4]. Trock et al. reported

\footnotetext{
* Correspondence: reirei513@hotmail.com

Department of Radiation Oncology, Tohoku University School of Medicine, Seiryou-machi 1-1, Aobaku, Sendai, Japan
}

that 5- and 10-year prostate cancer-specific survival rates were $88 \%$ and $62 \%$, respectively, for patients with no salvage treatment and $96 \%$ and $86 \%$, respectively, for patients who received salvage RT alone [5]. Recent studies have suggested that early RT is more effective than delayed RT. Some studies have demonstrated that pre-RT PSA is a prognostic factor [4,6-14]. Based on results of those studies, it seems that pre-RT PSA $<1.0 \mathrm{ng} / \mathrm{ml}$ as a cutoff value is a factor predicting PSA re-failure after salvage RT $[4,7,8,12]$, though according to a consensus panel report published by the American Society of Therapeutic Radiology and Oncology (ASTRO), early treatment (PSA $<1.5$ $\mathrm{ng} / \mathrm{ml}$ ) is more successful than later treatment [15]. However, even some patients with pre-RT PSA $<1.0 \mathrm{ng} / \mathrm{ml}$ who have received salvage $\mathrm{RT}$ have biochemical

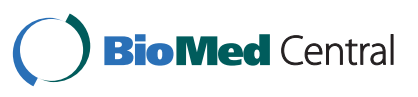


recurrence. The objective of this study was to evaluate prognostic factors in salvage RT after RP for patients with pre-RT PSA $<1.0 \mathrm{ng} / \mathrm{ml}$.

\section{Methods \\ Patients}

Between January 2000 and December 2009, 102 patients received salvage RT for biochemical failure after RP in Tohoku University Hospital and seven affiliated hospitals. Although the American Urological Association (AUA) defines biochemical recurrence following RP as initial serum PSA of $\geq 0.2 \mathrm{ng} / \mathrm{ml}$ with a second confirmatory level of $>0.2 \mathrm{ng} / \mathrm{ml}$ [16], the main criterion for salvage RT in this study was that PSA after RP was 0.1 $\mathrm{ng} / \mathrm{ml}$ or more or that PSA after RP was three consecutive increasing. Patients with massive local recurrence that was detectable by CT or MRI or patients with lymph node or distant metastasis were excluded from this study. Patients who continued to receive hormone therapy for PSA failure after RP but became resistant to the hormone therapy were also excluded.

\section{PSA doubling time}

PSA doubling time (PSADT) was calculated using PSA values above $0.1 \mathrm{ng} / \mathrm{ml}$ after RP until the start of salvage RT. PSADT was not calculated for patients who did not have PSA above $0.1 \mathrm{ng} / \mathrm{ml}$. PSADT was estimated by the natural $\log$ of $2(0.693)$ divided by the slope of the linear regression line of PSA over time [3].

\section{Radiotherapy}

The prostate bed, the bladder neck, the urethral anastomosis and the seminal vesicle bed (in the case of invasion to seminal vesicle) were defined as the clinical target volume (CTV) with references to preoperative computed tomography or magnetic resonance imaging. The planning target volume (PTV) included the CTV with a margin of approximately $1 \mathrm{~cm}$ in all directions. The leaf margin was $0.5 \mathrm{~cm}$ in all directions. Salvage RT was delivered using photon beams of $10 \mathrm{MV}$ or $15 \mathrm{MV}$ mostly with the four-field technique, three-dimensional conformal RT. The median RT dose was $64 \mathrm{~Gy}$ (range, 60-72 Gy). The numbers of patients receiving 60 Gy at 2 Gy daily, 62 Gy at 2 Gy daily, 64 Gy at 2 Gy daily, 64.8 Gy at 1.8 Gy daily, 70 Gy at 2 Gy daily and 72 Gy at 1.2 Gy per fraction twice daily (hyperfractionation) to the prostate bed were $18,1,67,12,3$ and 1, respectively. The RT dose was prescribed at the center of the PTV. None of the patients underwent whole pelvic irradiation.

\section{Follow-up}

Re-failure of PSA after salvage RT was defined as a serum PSA value of $0.2 \mathrm{ng} / \mathrm{ml}$ or more above the postradiotherapy nadir followed by another higher value, a continued rise in serum PSA despite salvage RT, or initiation of systemic therapy after completion of salvage RT [17]. The time to PSA re-failure after salvage RT was calculated from the first day of RT. Measurement of PSA after salvage RT was done at least once every 3 months.

\section{Statistical analysis}

Biochemical relapse-free survival (bRFS) was estimated using the Kaplan-Meier method, and the log-rank test was used to analyze differences between patient subgroups categorized by prognostic variables. Multivariate analysis was performed using the Cox proportional hazards regression model. Hazard ratios are presented for each prognostic factor. We evaluated pathologic tumor (pT) stage, surgical margin, Gleason score (GS), preoperative PSA, pre-RT PSA (Pre-RT PSA of patients who received hormone therapy was evaluated as that before hormone therapy.), PSADT, dose to the prostate bed, biological effective dose (BED) (calculated using $\alpha /$ $\beta=1.5$ according to the LQ model) [18], time from RP to the start of RT and hormonal therapy as prognostic factors. Multivariate analysis included factors with $\mathrm{p}<$ 0.10 in univariate analysis. All tests were two-sided, and statistical significance was set at the level of $\mathrm{p}<0.05$. Statistical analysis was performed using the Statistical Package for Social Sciences (SPSS) version 14.0 (SPSS, Chicago, IL).

\section{Toxicity}

Complications due to salvage RT were evaluated according to the common terminology criteria for adverse events (CTCAE) ver.4.0. Late toxicity was defined as a complication occurring more than three months after salvage RT.

\section{Ethics}

Written informed consent for treatment was obtained from all patients, and this retrospective study was performed according to the principles of the Declaration of Helsinki (2008).

\section{Results}

Patient and tumor characteristics are shown in Table 1. Median age at salvage RT was 67 years (range, 49-81 years). Median pre-RT PSA was 0.240 (range, 0.011$0.994 \mathrm{ng} / \mathrm{ml}$ ). Median preoperative PSA was $8.8 \mathrm{ng} / \mathrm{ml}$ (range, $1.6-120 \mathrm{ng} / \mathrm{ml}$ ). Median PSADT was 6.83 months (range, 0.58-41.9 months).

Hormone therapy was given to 29 patients before and/ or during salvage RT for a median period of 6 months (range, 1-18 months). Eleven of those patients continued to receive hormone therapy for a median period of 12 months (range, 1-15 months) after salvage RT. Two 
Table 1 Patients' characteristics

\begin{tabular}{|c|c|c|}
\hline Characteristic & No. & Median (range) \\
\hline Age at salvage RT (years) & & $67(49-81)$ \\
\hline \multicolumn{3}{|l|}{ Pathologic tumor stage } \\
\hline $\mathrm{T} 1$ & 2 & \\
\hline $\mathrm{T} 2$ & 41 & \\
\hline T3 & 57 & \\
\hline T4 & 1 & \\
\hline Unknown & 2 & \\
\hline \multicolumn{3}{|l|}{ Surgical margin } \\
\hline Positive & 48 & \\
\hline Negative & 51 & \\
\hline Unknown & 3 & \\
\hline \multicolumn{3}{|l|}{ Gleason score } \\
\hline$\leq 6$ & 31 & \\
\hline 7 & 35 & \\
\hline $8 \geq$ & 31 & \\
\hline Unknown & 5 & \\
\hline Preoperative PSA (ng/ml) & & $8.8(1.6-120)$ \\
\hline$<10$ & 58 & \\
\hline$\geq 10$ & 44 & \\
\hline Pre-RT PSA (ng/ml) & & $0.240(0.011-0.994)$ \\
\hline$<0.25$ & 52 & \\
\hline$\geq 0.25$ & 50 & \\
\hline PSA doubling time (months) & & $6.83(0.58-41.9)$ \\
\hline$<7$ & 43 & \\
\hline$\geq 7$ & 43 & \\
\hline Not available & 16 & \\
\hline RT dose (Gy) (BED, $\alpha / \beta=1.5)$ & & $\begin{array}{c}64(149.3)(60-72[129.6- \\
163.3])\end{array}$ \\
\hline 60 at 2 daily (140.0) & 18 & \\
\hline 62 at 2 daily (144.7) & 1 & \\
\hline 64 at 2 daily (149.3) & 67 & \\
\hline 64.8 at 1.8 daily (142.6) & 12 & \\
\hline 70 at 2 daily (163.3) & 3 & \\
\hline $\begin{array}{l}72 \text { at } 1.2 \text { per fraction twice daily (HF) } \\
\qquad(129.6)\end{array}$ & 1 & \\
\hline Time from RP to RT (months) & & $21(5-99)$ \\
\hline$<24$ & 56 & \\
\hline$\geq 24$ & 46 & \\
\hline \multicolumn{3}{|l|}{ Hormone therapy } \\
\hline Done & 29 & \\
\hline Not done & 73 & \\
\hline
\end{tabular}

Abbreviations: $\mathrm{RT}$ = radiotherapy, $\mathrm{PSA}=$ prostate-specific antigen, $\mathrm{BED}=$ biological effective dose, $\mathrm{HF}=$ hyperfractionation, $\mathrm{RP}=$ radical prostatectomy

patients received hormone therapy for PSA failure and stopped the therapy because of decrease in PSA but restarted the therapy when PSA had increased again. No patient received adjuvant hormone therapy after RP.

The median follow-up period from the start of salvage RT was 44 months (range, 11-103 months). The 4-year overall survival rate was $97.3 \%$ (95\% confidence interval [95\% CI]: $93.6-100 \%)$. No patient died of prostate cancer, though one patient died of esophageal cancer and one patient died of bile duct cancer. PSA decreased in 64 of the 73 patients who received salvage RT after RP without hormone therapy. Forty-three patients had re-failure after salvage RT at the last observation date. The 4-year bRFS rate was 50.9\% (95\% CI: 39.4-62.5\%) (Figure 1). Multiple lung metastases occurred in one patient 17 months after salvage RT, and bone metastases occurred in two patients 36 and 43 months after salvage RT.

Results of the log-rank tests presented in Table 2 show the 4-year bRFS for each prognostic factor before salvage RT. It was found that $\mathrm{pT}$ stage $(\mathrm{p}<0.001)$ and preoperative PSA $(\mathrm{p}=0.037)$ were significant prognostic factors. The 4-year bRFS for pT1-2 and pT3-4 were 79.2\% (95\% CI: 66.0-92.3\%) and 31.7\% (95\% CI: $17.0-$ $46.4 \%$ ), respectively (Figure 2). We also analyzed bRFS for extracapsular extension and seminal vesicle invasion. The 4-year bRFS for positive and negative extracapsular extension were 79.9\% (95\% CI: 65.4-94.5\%) and 35.9\% (95\% CI: $21.0-49.8 \%)(\mathrm{p}=0.003)$, respectively. The 4year bRFS for positive and negative seminal vesicle invasion were $56.9 \%$ (95\% CI: $44.3-71.0 \%)$ and $19.0 \%(95 \%$ CI: $0-39.1 \%)(p=0.004)$, respectively. The 4-year bRFS for preoperative PSA $<10 \mathrm{ng} / \mathrm{ml}$ and $\geq 10 \mathrm{ng} / \mathrm{ml}$ were 62.0\% (95\% CI: $47.7-76.3 \%$ ) and 39.3\% (95\% CI: $22.5-$ $56.0 \%$ ), respectively (Figure 3 ). Although not significant, PSADT $(\mathrm{p}=0.059)$ and RT dose $(\mathrm{p}=0.068)$ tended to be prognostic factors. The 4-year bRFS for PSADT $<7$ months and $\geq 7$ months were $34.6 \%$ (95\% CI: 17.5 $51.8 \%$ ) and $62.2 \%$ (95\% CI: 46.7-77.7\%), respectively

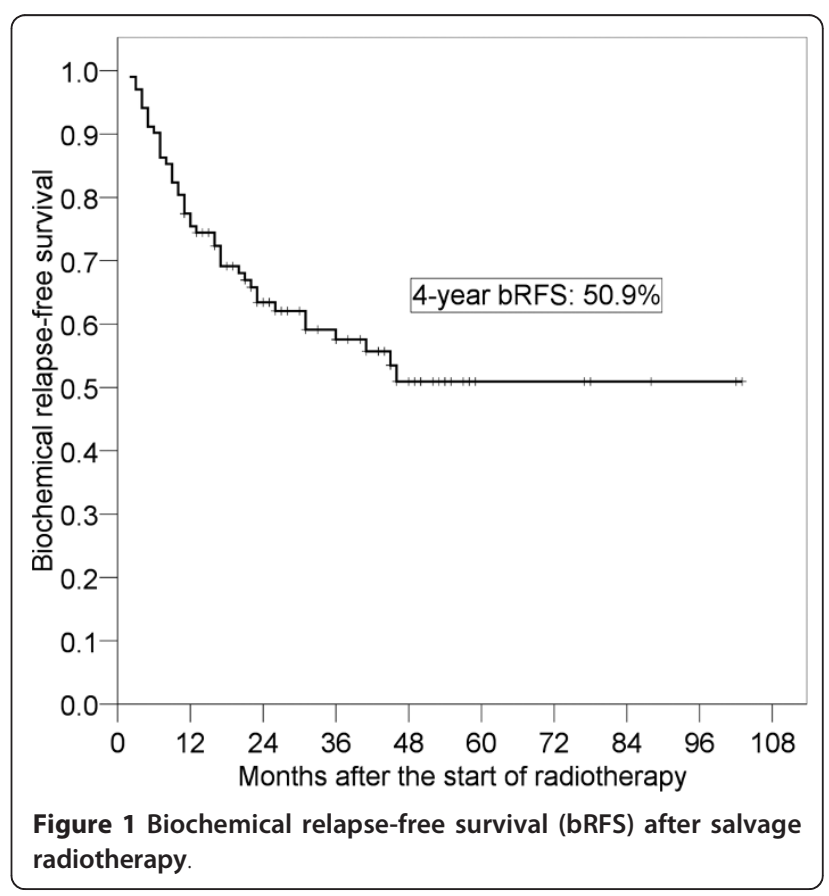


Table 2 Results of log-rank tests

\begin{tabular}{|c|c|c|}
\hline Factor & 4-year bRFS (\%) (95\% Cl) & $\mathrm{p}$ value \\
\hline Pathologic tumor stage & & $<0.001$ \\
\hline $\mathrm{T} 1-2$ & $79.2(66.0-92.3)$ & \\
\hline T3-4 & $31.7(17.0-46.4)$ & \\
\hline Surgical margin & & 0.652 \\
\hline Positive & $48.6(32.0-65.1)$ & \\
\hline Negative & $57.1(42.7-71.4)$ & \\
\hline Gleason score & & 0.189 \\
\hline$\leq 7$ & $58.9(44.5-73.3)$ & \\
\hline$\geq 8$ & $35.2(14.7-51.5)$ & \\
\hline Preoperative PSA (ng/ml) & & 0.037 \\
\hline$<10$ & $62.0(47.7-76.3)$ & \\
\hline$\geq 10$ & $39.3(22.5-56.0)$ & \\
\hline Pre-RT PSA (ng/ml) & & 0.620 \\
\hline$<0.25$ & $54.5(37.5-71.6)$ & \\
\hline$\geq 0.25$ & $45.9(30.2-64.9)$ & \\
\hline PSA doubling time (months) & & 0.059 \\
\hline$<7$ & $34.6(17.5-51.8)$ & \\
\hline$\geq 7$ & $62.2(46.7-77.7)$ & \\
\hline RT dose (Gy) & & 0.068 \\
\hline$<64$ & $36.8(15.2-58.5)$ & \\
\hline$\geq 64$ & $51.7(37.6-65.9)$ & \\
\hline $\operatorname{BED}(\mathrm{Gy})(\alpha / \beta=1.5)$ & & 0.213 \\
\hline$<145$ & $41.4(23.5-59.3)$ & \\
\hline$\geq 145$ & $54.3(39.5-69.1)$ & \\
\hline Time from RP to RT (months) & & 0.310 \\
\hline$<24$ & $45.2(29.1-61.4)$ & \\
\hline$\geq 24$ & $57.4(40.9-73.9)$ & \\
\hline Hormone therapy & & 0.627 \\
\hline Done & $50.5(20.2-72.9)$ & \\
\hline Not done & $50.7(37.6-63.7)$ & \\
\hline
\end{tabular}

Abbreviations: bRFS = biochemical relapse-free survival, RT = radiotherapy, $\mathrm{PSA}=$ prostate-specific antigen, $\mathrm{BED}=$ biological effective dose, $\mathrm{RP}=$ radical prostatectomy, $\mathrm{Cl}=$ confidence interval

(Figure 4). The 4-year bRFS for dose $<64$ Gy and $\geq 64$ Gy were $36.8 \%$ (95\% CI: $15.2-58.5 \%)$ and $52.7 \%$ (95\% CI: 39.5-69.1\%), respectively (Figure 5). When we evaluated bRFS in 73 patients without hormone therapy, pT stage $(\mathrm{p}<0.001)$ and preoperative PSA $(\mathrm{p}=0.018)$ were also significant prognostic factors. In those patients, the 4year bRFS for pT1-2 and pT3-4 were 78.5\% (95\% CI: 62.9-94.2\%) and $29.6 \%$ (95\% CI: $13.7-45.6 \%)$, respectively, and the 4-year bRFS for preoperative PSA $<10$ $\mathrm{ng} / \mathrm{ml}$ and $\geq 10 \mathrm{ng} / \mathrm{ml}$ were $64.0 \%$ (95\% CI: 48.5-79.5\%) and $33.9 \%$ (95\% CI: $14.3-53.6 \%)$, respectively.

In 79 patients who received 64 or 64.8 Gy to the prostate bed, the 4-year bRFS for pT1-2 and pT3-4 were 85.5\% (95\% CI: 73.6-97.3\%) and 28.8\% (95\% CI: $7.87-$ $49.8 \%)(\mathrm{p}<0.001)$, respectively (Figure 6).

Multivariate analysis was evaluated by $\mathrm{pT}$ stage, preoperative PSA, PSADT and RT dose. Only pT stage was a significant prognostic factor $(\mathrm{p}=0.003)$ and the

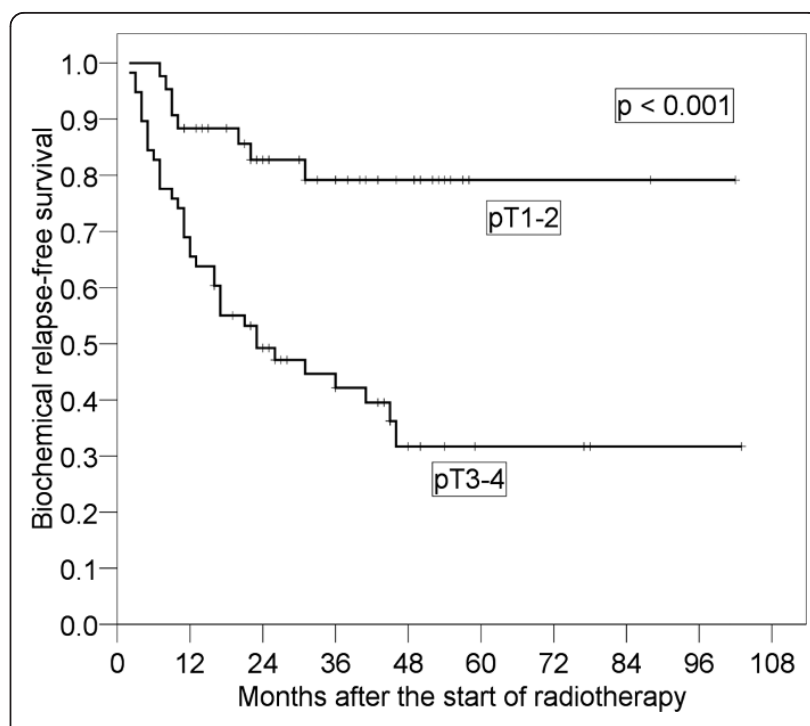

Figure 2 Four-year biochemical relapse-free survival in patients with pT3-4 and that in patients with pT1-2.

hazard ratio (HR) with pT3-4 was 3.512 (95\% CI: 1.5358.037) (Table 3). After adjusting for $\mathrm{pT}$, none of the other variables retained prognostic significance.

Grade 2 late urinary tract complication was observed in one patient who suffered from urinary occlusion. Grade 3 late rectal complication was observed in one patient who suffered from rectal bleeding.

\section{Discussion}

Moreira et al. reported that the 1-, 3- and 5-year risks of receiving any salvage treatment after RP were $29 \%, 48 \%$

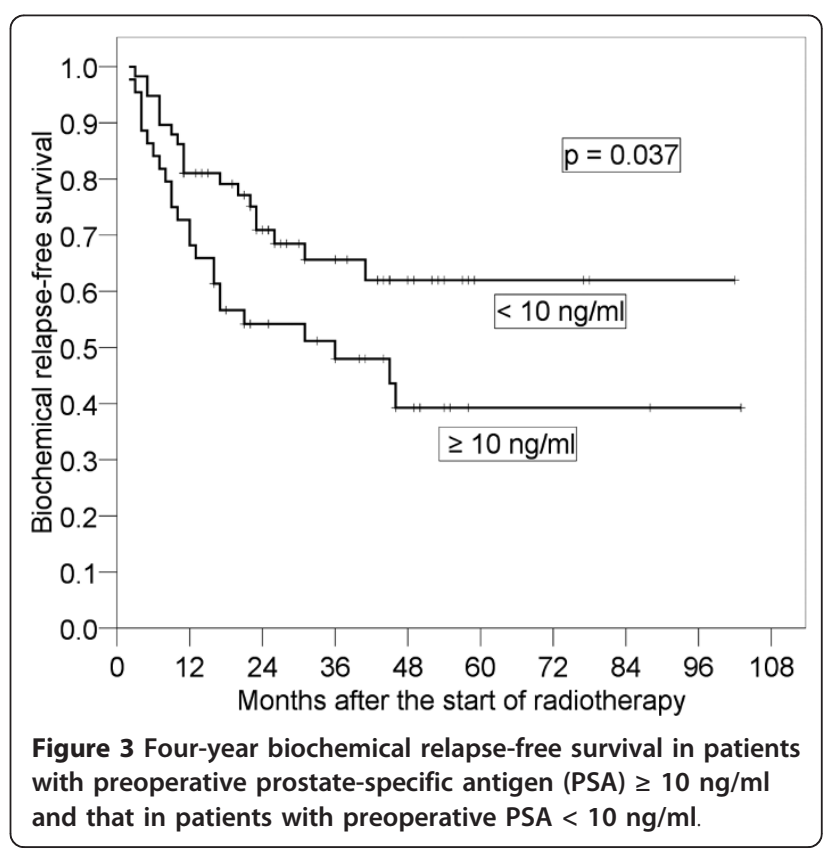




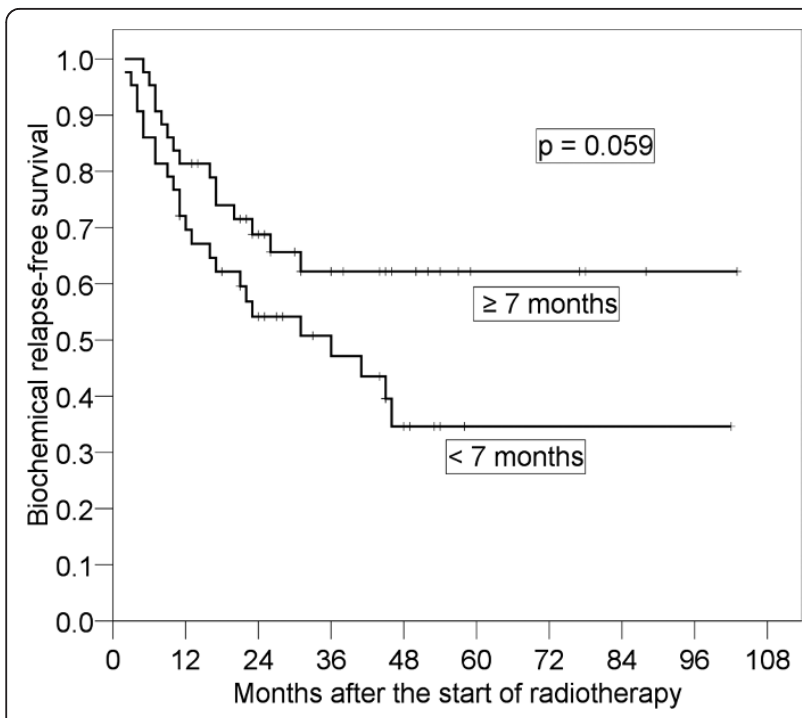

Figure 4 Four-year biochemical relapse-free survival in patients with prostate specific-antigen doubling time (PSADT) $\geq 7$ months and that in patients with PSADT $<7$ months.

and $53 \%$, respectively [19]. Salvage RT is one of the major treatments for biochemical recurrence after RP, and many studies have shown that salvage RT is effective [4,6-14,20-27]. In our study, PSA decreased in 64 of the 73 patients who received salvage RT after RP without hormone therapy, suggesting that this treatment was effective for biochemical failure after RP. Those patients might have had at least a component local disease. PSA did not decrease in the patient who had multiple lung metastases. Although comparison with results of

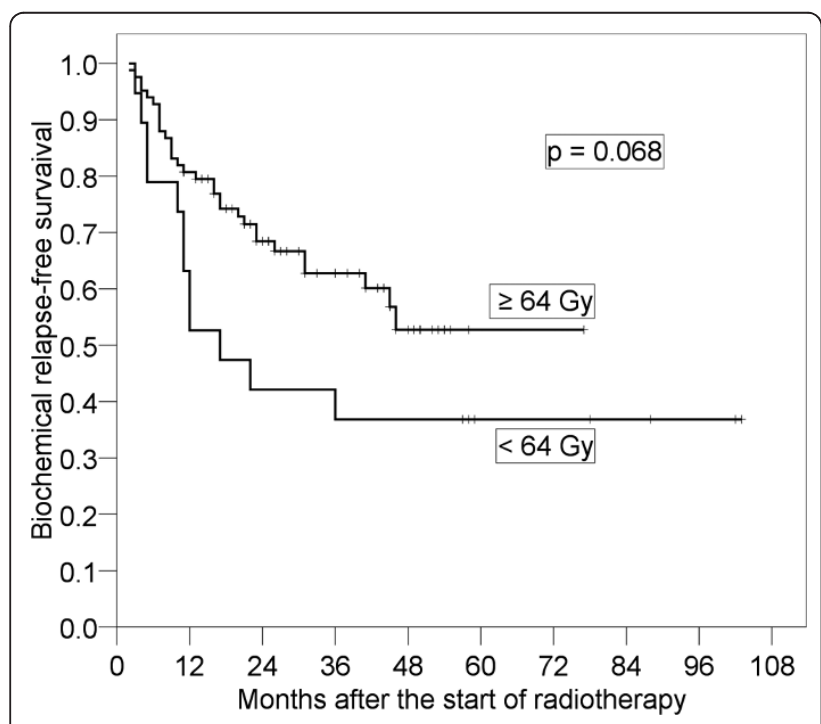

Figure 5 Four-year biochemical relapse-free survival in patients with radiotherapy (RT) dose $\geq 64$ Gy and that in patients with RT dose $<64 \mathrm{~Gy}$.

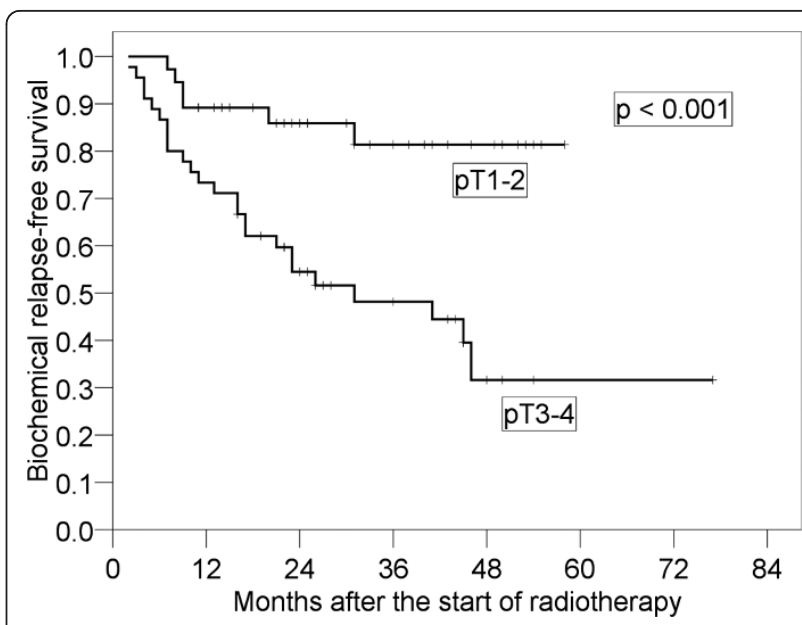

Figure 6 Four-year biochemical relapse-free survival for pT3-4 and that for pT1-2 in patients who received 64 or 64.8 Gy to the prostate bed.

previous studies might not be appropriate differences in race, conditions under which salvage RT was performed and criteria of re-failure after salvage RT, bRFS in the present study was similar to that in previous studies (Table 4). However, significant prognostic factors for refailure of salvage RT in those studies were different. Some of those studies showed that pre-RT PSA $<1.0$ $\mathrm{ng} / \mathrm{ml}$ was a prognostic factor $[4,7,8,12]$. In those studies, median values of pre-RT PSA were higher (0.7-4.5 $\mathrm{ng} / \mathrm{ml})$ than that in the present study $(0.240 \mathrm{ng} / \mathrm{ml})$. However, even some patients with pre-RT PSA $<1.0$ $\mathrm{ng} / \mathrm{ml}$ who have received salvage $\mathrm{RT}$ experience biochemical recurrence. Therefore, we retrospectively evaluated prognostic factors in salvage RT for patients with pre-RT PSA $<1.0 \mathrm{ng} / \mathrm{ml}$.

Table 3 Multivariate analysis of parameters with bRFS

\begin{tabular}{ccc}
\hline Factors & Hazards ratio $(\mathbf{9 5} \% \mathbf{C l})$ & $\mathbf{p}$ value \\
\hline Pathologic tumor stage & Reference & 0.003 \\
T1-2 & $3.512(1.535-8.037)$ & \\
T3-4 & & 0.177 \\
Preoperative PSA $(\mathrm{ng} / \mathrm{ml})$ & Reference & \\
$<10$ & $1.566(0.816-3.006)$ & \\
$\geq 10$ & & 0.272 \\
PSADT (months) & Reference & \\
$<7$ & $0.686(0.350-1.344)$ & \\
$\geq 7$ & & 0.357 \\
RT dose (Gy) & Reference & \\
$<64$ & $0.712(0.345-1.469)$ & \\
$\geq 64$ &
\end{tabular}

Abbreviations: bRFS $=$ biochemical relapse-free survival, PSA $=$ prostatespecific antigen, PSADT = prostate-specific antigen doubling time, RT = radiotherapy, $\mathrm{RP}=$ radical prostatectomy, $\mathrm{Cl}=$ confidence interval 
Table 4 Past studies on salvage RT for biochemical recurrence after RP

\begin{tabular}{|c|c|c|c|c|}
\hline Study & Patients ( $\mathrm{n}$ ) & Median pre-RT PSA (ng/ml) & prognostic factors after salvage RT & bRDS(\%) \\
\hline Hagan et al [7] & 91 & 4.5 & pre-RT PSA $(<1.0 \mathrm{ng} / \mathrm{ml})$ & 55 (5-year) \\
\hline Quero et al [8] & 59 & 1.43 & pre-RT PSA $(<1.0 \mathrm{ng} / \mathrm{ml})$ & 41.2 (5-year) \\
\hline Macdonald et al [9] & 121 & 1.4 & pre-RT PSA $(<0.2 \mathrm{ng} / \mathrm{ml})$ & NA \\
\hline Anscher et al [10] & 89 & 1.4 & pre-RT PSA $(<2.5 \mathrm{ng} / \mathrm{ml}), \mathrm{RT}$ dose (> $65 \mathrm{~Gy})$ & 50 (4-year) \\
\hline Chawla et al [20] & 54 & 1.3 & Gleason score $(\leq 6)$, time to detectable postoperative PSA & 35 (5-year) \\
\hline Tsien et al [21] & 57 & 1.2 & Gleason score $(<$ or $=7)$ & 58 (5-year) \\
\hline Neuhof et al [4] & 171 & 1.1 & Gleason score $(<7)$, pre-RT PSA $(<1.0 \mathrm{ng} / \mathrm{ml})$ & 35.1 (5-year) \\
\hline Jacinto et al [22] & 43 & 0.87 & PSADT (> 4.0 months) & 71 (3-year) \\
\hline Taylor et al [23] & 66 & 0.8 & delayed rise in PSA after RP & 66 (5-year) \\
\hline Pazona et al [11] & 307 & 0.8 & pre-RT PSA $(<1.3 \mathrm{ng} / \mathrm{ml})$, Seminal vesicle & 40 (5-year) \\
\hline Stephenson et al [6] & 501 & 0.72 & $\begin{array}{c}\text { Gleason score }(\leq 7) \text {, pre-RT PSA }(\leq 2.0 \mathrm{ng} / \mathrm{ml}) \\
\text { PSADT ( }>10 \text { months })\end{array}$ & 45 (4-year) \\
\hline Buskirk et al [12] & 368 & 0.7 & pT2-3a, Gleason score $(\leq 7)$, Pre-RT PSA $(<1.0 \mathrm{ng} / \mathrm{ml})$ & 46 (5-year) \\
\hline Bernard et al [13] & 364 & 0.6 & RT dose (> $66.6 \mathrm{~Gy}$, patients with pre-RT PSA $<0.6 \mathrm{ng} / \mathrm{ml}$ ) & 50 (5-year) \\
\hline Ward et al [24] & 211 & 0.6 & PSADT (> 12 months) & 34 (10-year) \\
\hline King et al [25] & 37 & 0.49 & $\operatorname{PSAV}(\leq 1.0 \mathrm{ng} / \mathrm{ml} /$ year $)$ & NA \\
\hline Wiegel et al [26] & 162 & 0.33 & PSA undetectable after salvage $\mathrm{RT}(<0.1 \mathrm{ng} / \mathrm{ml})$ & 54 (3.5-year) \\
\hline Tomita et al [27] & 51 & 0.25 & PSADT (> 3.0 months), Gleason Score, RT dose ( $\geq 60$ Gy) & 55.1 (3-year) \\
\hline Terai et al [14] & 37 & 0.146 & CT1-2, pT2, pre-RT PSA (>0.15 ng/ml) & 54 (5-year) \\
\hline
\end{tabular}

Abbreviations: $\mathrm{RT}=$ radiotherapy, $\mathrm{RP}=$ radical prostatectomy, PSA = prostate-specific antigen, bRDS = biochemical relapse-free survival, PSADT = PSA doubling time, PSAV = PSA velocity, NA = not available

In the present study, pre-RT PSA was not a significant factor. Therefore, there might be no need for early salvage $\mathrm{RT}$ in patients with pre-RT PSA $<1.0 \mathrm{ng} / \mathrm{ml}$. However, early or more intense salvage RT in cases of high risk for recurrence (e.g., pT3-4 and preoperative PSA > $10 \mathrm{ng} / \mathrm{ml}$ ) even with PSA $<1.0 \mathrm{ng} / \mathrm{ml}$ might be necessary because the rate of biochemical recurrence after salvage RT is relatively high even in patients with preRT PSA $<1.0 \mathrm{ng} / \mathrm{ml}$. Further investigation of the prognostic factors of salvage RT other than pre-RT PSA in patients with high risk for recurrence is needed.

Recently, PSADT has been utilized as a prognostic factor for prostatectomy. Pound et al. found that PSADT predicted the likelihood of subsequent development of metastatic disease [3]. Freedland et al. found that prostate cancer-specific survival of patients with PSADT $<9$ months (especially $<3$ months) was worse than that of patients with PSADT $>15$ months [28]. Some past studies have demonstrated that PSADT was also a prognostic factor of salvage RT $[6,22,24,27]$. Median pre-RT PSA in some of those studies was $1.0 \mathrm{ng} / \mathrm{ml}$ or less. In a study by Trock et al. with median pre-RT PSA $<1.0 \mathrm{ng} / \mathrm{ml}$, salvage RT performed within 2 years after biochemical recurrence significantly improved prostate cancer-specific survival among patients with PSADT of less than 6 months (HR: 0.14) [5]. Although not significant in our study, the 4-year bRFS rate of patients with PSADT $<7$ months was worse than that of patients with PSADT $\geq 7$ months. The reason why PSADT was not a significant factor in our study might be that there were 16 patients for whom PSADT data were not available and the number of cases for analysis was insufficient. If pre-RT PSA is $<1.0 \mathrm{ng} / \mathrm{ml}$, we might be able to refer to PSADT for starting salvage RT. Although PSADT is widely used to predict outcomes such as time to progression, underlying the impressive evidence of predictive value and prognostic value of PSADT are many basic questions about how it should be calculated [29]. Although Arlen et al. demonstrated that PSA kinetics was all calculated from the point of failure of $0.2 \mathrm{ng} / \mathrm{ml}$ [30], PSADT was calculated using PSA values above $0.1 \mathrm{ng} / \mathrm{ml}$ after RP in our study.

In our study, only pT3-4 was a significant factor predicting PSA re-failure after salvage RT in multivariate analysis. In a study by Wiegel et al., bRFS for pT3-4 was worse than that for pT2 (p = 0.047) [26]. Although bRFS for pT3-4 was poor in patients with PSA $<1.0 \mathrm{ng} /$ $\mathrm{ml}$, there may be some room for improvement in RT for patients with pT3-4. One method for improving bRFS in patients with pT3-4 is postoperative RT. According to the European Organization for Research and Treatment of Cancer (EORTC) 22911, adjuvant external irradiation after radical prostatectomy improves biochemical progression-free survival and local control in patients with positive margins [31]. In that study, the 5 -year biochemical progression-free survival rates for patients in the Irradiation group and the Wait and see group with one or more pathological risk factors (capsule perforation, positive surgical margins and invasion of seminal vesicles) were $74.0 \%$ and $52.6 \%$, respectively. 
In the Southwest Oncology Group (SWOG) 8794, adjuvant radiotherapy for patients with pT3 after RP resulted in significant reduction of the risk for PSA relapse (median PSA relapse-free survival: 10.3 years for radiotherapy vs. 3.1 years for observation) [32]. In their further study, metastasis-free survival was significantly greater with adjuvant radiotherapy (93 of 214 patients on the radiotherapy arm vs 114 of 211 patients on the observation arm) and survival improved significantly with adjuvant radiotherapy (88 deaths in 214 patients on the radiotherapy arm vs 110 deaths in 211 patients on the observation arm) [33]. In a study by Jereczek-Fossa et al., failure-free survival of postoperative RT patients was significantly longer than that of patients who had undergone salvage RT (4-year biochemical control rates: $81.7 \%$ and $60.5 \%$, respectively) [34]. Postoperative RT was suggested to be more effective than salvage RT in patients with pT3-4. The reason why bRFS for patients with pT3-4 is poor may also be that these patients already have latent lymph node metastases. Spiotto et al. reported that whole pelvic RT resulted in superior bRFS compared with prostate bed RT, especially in high-risk patients with GS $\geq 8$, preoperative PSA $>20 \mathrm{ng} / \mathrm{ml}$, pT3, or pathologic lymph node involvement (5-year bRFS: $47 \%$ vs $21 \%$ ) [35]. Whole pelvic RT might also be an effective treatment.

The ASTRO consensus guidelines suggest a minimum of 64 Gy at conventional dose fractionation [15]. In our study, bRFS of patients treated with a dose $\geq 64$ Gy tended to be better than that of patients treated with a dose < 64 Gy (51.7\% [95\% CI: 38.5-67.0\%] vs. 36.8\% [95\% CI: $15.2-58.5 \%$ ], $\mathrm{p}=0.068$ ). At least 64 Gy may be required for salvage $\mathrm{RT}$ after RP. King et al. found that salvage RT with 70 Gy was superior to that with 60 Gy (5-year bRFS: $58 \%$ vs. $25 \%$ ) [36]. Bernard et al. found that doses higher than 66.6 Gy resulted in decreased risk of biochemical failure after salvage RT [13]. King et al. reported that the dose-response relationships of salvage $\mathrm{RT}$ and definitive external beam radiotherapy for localized prostate cancer were similar [37]. Only in patients treated with 64 or $64.8 \mathrm{~Gy}$, the 4-year bRFS for patients with pT3-4 was much worse than that for patients with pT1-2 (85.5\% [95\% CI: 73.6-97.3\%] and 28.8\% [95\% CI: 7.87-49.8\%], respectively, $\mathrm{p}<0.001$ ), (Figure 6). This result suggested that 64 Gy in patients with pT3-4 might be insufficient. The results of a study by Cozzarini et al. provided strong support for the use of RT at doses $\geq 70$ Gy in pT3-4 patients [38]. Therefore, patients with pT3-4 might need dose escalation for salvage RT after RP.

There were some limitations in the present study. First, data for patients who received hormone therapy prior to RT may confound the analysis and lessen the significance of some risk factors. The value of PSA is strongly affected by hormone therapy. Therefore, we also evaluated bRFS in 73 patients without hormone therapy. Although the number of samples became small, the result was similar. Second, we analyzed bRFS in the present study retrospectively, and there were two separate definitions of the criterion for salvage RT. The criteria were slightly different between previous studies. AUA defines biochemical recurrence following RP as initial serum PSA of $\geq 0.2 \mathrm{ng} / \mathrm{ml}$ with a second confirmatory level of $>0.2 \mathrm{ng} / \mathrm{ml}$ [16]. We analyzed bRFS in 65 patients with pre-PSA of $\geq 0.2 \mathrm{ng} / \mathrm{ml}$. The results showed that only $\mathrm{pT}$ was only a siginificant prognostic factor $(p<0.001)$. The bRFS after salvage RT might be affected by pT3-4 after all, even if we consider those limitations.

\section{Conclusion}

Salvage RT is an effective treatment for patients with biochemical recurrence after RP. In patients with PSA < $1.0 \mathrm{ng} / \mathrm{ml}, \mathrm{pT}$ stage and preoperative PSA were prognostic factors of bRFS. In particular, pT3-4 had a high risk for biochemical recurrence after salvage $\mathrm{RT}$, and more intense treatment is recommended for such patients.

\section{Authors' contributions}

$\mathrm{RU}$ participated in data collection, performed the statistical analysis and drafted the manuscript. HA and YO conceived of the study and helped to draft the manuscript. $\mathrm{KJ}$ participated in its design and coordination and helped to draft the manuscript. HM, KT, KF, TS, TS, MK, KN, ES helped with collection of data. YT and SY helped to draft the manuscript. All authors read and approved the final manuscript.

\section{Competing interests}

The authors declare that they have no competing interests.

Received: 4 August 2011 Accepted: 5 November 2011

Published: 5 November 2011

\section{References}

1. Han M, Partin AW, Pound CR, Epstein JI, Walsh PC: Long-term biochemical disease-free and cancer-specific survival following anatomic radical retropubic prostatectomy: The 15-year Johns Hopkins experience. Urol Clin North Am 2001, 28:555-565.

2. Ward JF, Moul JW: Rising prostate-specific antigen after primary prostate cancer therapy. Nat Clin Pract Urol 2005, 2:174-182.

3. Pound CR, Partin AW, Eisenberger MA, Chan DW, Pearson JD, Walsh PC: Natural history of progression after PSA elevation following radical prostatectomy. JAMA 1999, 281:1591-1597.

4. Neuhof D, Hentschel T, Bischof M, Sroka-Perez G, Hohenfellner M, Debus J: Long-term results and predictive factors of three-dimensional conformal salvage radiotherapy for biochemical relapse after prostatectomy. Int J Radiat Oncol Biol Phys 2007, 67:1411-1417.

5. Trock BJ, Han M, Freedland SJ, Humphreys EB, DeWeese TL, Partin AW, Walsh PC: Prostate cancer-specific survival following salvage radiotherapy vs observation in men with biochemical recurrence after radical prostatectomy. JAMA 2008, 299:2760-2769.

6. Stephenson AJ, Shariat SF, Zelefsky MJ, Kattan MW, Butler EB, Teh BS, Klein EA, Kupelian PA, Roehrborn CG, Pistenmaa DA, Pacholke HD, Liauw SL, Katz MS, Leibel SA, Scardino PT, Slawin KM: Salvage radiotherapy for recurrent prostate cancer after radical prostatectomy. JAMA 2004, 291:1325-1332. 
7. Hagan M, Zlotecki R, Medina C, Tercilla O, Rivera I, Wajsman Z: Comparison of adjuvant versus salvage radiotherapy policies for postprostatectomy radiotherapy. Int I Radiat Oncol Biol Phys 2004, 59:329-340.

8. Quero L, Mongiat-Artus P, Ravery V, Maylin C, Desgrandchamps F, Hennequin C: Salvage radiotherapy for patients with PSA relapse after radical prostatectomy: a single institution experience. BMC Cancer 2008, 8:26.

9. Macdonald OK, D'Amico AV, Sadetsky N, Shrieve DC, Carroll PR: Predicting PSA failure following salvage radiotherapy for a rising PSA postprostatectomy: from the CaPSURE database. Urol Oncology 2008, 26:271-275.

10. Anscher MS, Clough R, Dodge R: Radiotherapy for a rising prostatespecific antigen after radical prostatectomy: the first 10 years. Int $\mathrm{J}$ Radiat Oncol Biol Phys 2000, 48:369-375.

11. Pazona JF, Han M, Hawkins SA, Roehl KA, Catalona WJ: Salvage radiation therapy for prostate specific antigen progression following radical prostatectomy: 10-year outcome estimates. J Urol 2005, 174:1282-1286.

12. Buskirk SJ, Pisansky TM, Schild SE, Macdonald OK, Wehle MJ, Kozelsky TF, Collie AC, Ferrigni RG, Myers RP, Prussaki KA, Heckman MG, Crook JE, Parker AS, Igel TC: Salvage radiotherapy for isolated prostate specific antigen increase after radical prostatectomy: evaluation of prognostic factors and creation of a prognostic scoring system. J Urol 2006, 176:985-990.

13. Bernard JR Jr, Buskirk SJ, Heckman MG, Diehl NN, Ko SJ, Macdonald OK, Schild PE, Pisansky TM: Salvage radiotherapy for rising prostate-specific antigen levels after radical prostatectomy for prostate cancer: doseresponse analysis. Int J Radiat Oncol Biol Phys 2009, 76:735-740.

14. Terai A, Matsui $Y$, Yoshimura $K$, Arai $Y$, Dodo $Y$ : Salvage radiotherapy for biochemical recurrence after radical prostatectomy. BJU Int 2005, 96:1009-1013.

15. Cox JD, Gallagher MJ, Hammond EH, Kaplan RS, Schellhammer PF: Consensus statements on radiation therapy of prostate cancer: guidelines for prostate re-biopsy after radiation and for radiation therapy with rising prostate-specific antigen levels after radical prostatectomy. American Society for Therapeutic Radiology and Oncology Consensus Panel. J Clin Oncol 1999, 17:1155-1163.

16. Cookson MS, Aus G, Burnett AL, Canby-Hagino ED, D'Amico AV, Dmochowski RR, Eton DT, Forman JD, Goldenberg SL, Hernandez J, Higano CS, Kraus SR, Moul JW, Tangen C, Thrasher JB, Thompson I: Variation in the definition of biochemical recurrence in patients treated for localized prostate cancer: the American Urological Association Prostate Guidelines for Localized Prostate Cancer Update Panel report and recommendations for a standard in the reporting of surgical outcomes. J Urol 2007, 177:540-545.

17. Stephenson AJ, Scardino PT, Kattan MW, Pisansky TM, Slawin KM, Klein EA, Anscher MS, Michalski JM, Sandler HM, Lin DW, Forman JD, Zelefsky MJ, Kestin LL, Roehrborn CG, Catton CN, DeWeese TL, Liauw SL, Valicenti RK, Kuban DA, Pollack A: Predicting the outcome of salvage radiation therapy for recurrent prostate cancer after radical prostatectomy. I Clin Oncol 2007, 25:2035-2041.

18. Brenner DJ, Hall EJ: Fractionation and protraction for radiotherapy of prostate carcinoma? Int J Radiat Oncol Biol Phys 1999, 43:1095-1101.

19. Moreira DM, Banez LL, Presti JC Jr, Aronson WJ, Terris MK, Kane CJ, Amling CL, Freedland SJ: Predictors of secondary treatment following biochemical recurrence after radical prostatectomy: results from the Shared Equal Access Regional Cancer Hospital database. BJU Int 2010 105:28-33.

20. Chawla AK, Thakral HK, Zietman AL, Shipley WU: Salvage radiotherapy after radical prostatectomy for prostate adenocarcinoma: analysis of efficacy and prognostic factors. Urology 2002, 59:726-731.

21. Tsien C, Griffith KA, Sandler HM, McLaughlin P, Sanda MG, Montie J, Reddy S, Hayman JA: Long-term results of three-dimensional conformal adjuvant and salvage radiotherapy after radical prostatectomy. Urology 2003, 62:93-98

22. Jacinto $A A$, Fede $A B$, Fagundes $L A$, Salvajoli JV, Castilho MS, Viani GA, Fogaroli RC, Novaes PE, Pellizon AC, Maia MA, Ferrigno R: Salvage radiotherapy for biochemical relapse after complete PSA response following radical prostatectomy: outcome and prognostic factors for patients who have never received hormonal therapy. Radiat Oncol 2007, 2:8.
23. Taylor N, Kelly JF, Kuban DA, Babaian RJ, Pisters LL, Pollack A: Adjuvant and salvage radiotherapy after radical prostatectomy for prostate cancer. Int J Radiat Oncology Biol Phys 2003, 56:755-763.

24. Ward JF, Zincke H, Bergstralh EJ, Slezak JM, Blute ML: Prostate specific antigen doubling time subsequent to radical prostatectomy as a prognosticator of outcome following salvage radiotherapy. J Urol 2004, 172:2244-2248.

25. King CR, Presti JC, Brooks JD, Gill H, Spiotto MT: Postoperative prostatespecific antigen velocity independently predicts for failure of salvage radiotherapy after prostatectomy. Int $J$ Radiat Oncol Biol Phys 2008, 70:1472-1477.

26. Wiegel T, Lohm G, Bottke D, Hocht S, Miller K, Siegmann A, Schostak M, Neumann K, Hinkelbein W: Achieving an undetectable PSA after radiotherapy for biochemical progression after radical prostatectomy is an independent predictor of biochemical outcome-results of a retrospective study. Int I Radiat Oncol Biol Phys 2009, 73:1009-1016.

27. Tomita N, Kodaira T, Furutani K, Tachibana H, Hasegawa Y, Mizoguchi N, Hayashi N: Early salvage radiotherapy for patients with PSA relapse after radical prostatectomy. J Cancer Res Clin Oncol 2009, 135:1561-1567.

28. Freedland SJ, Humphreys EB, Mangold LA, Eisenberger M, Dorey FJ, Walsh PC, Partin AW: Risk of prostate cancer-specific mortality following biochemical recurrence after radical prostatectomy. JAMA 2005, 294:433-439

29. Daskivich TJ, Regan MM, Oh WK: Prostate specific antigen doubling time calculation: not as easy as 1, 2, 4. J Urol 2006, 176:1927-1937.

30. Arlen PM, Bianco F, Dahut WL, D'Amico A, Figg WD, Freedland SJ, Gulley JL, Kantoff PW, Kattan MW, Lee A, Regan MM, Sartor O: Prostate Specific Antigen Working Group. Prostate Specific Antigen Working Group guidelines on prostate specific antigen doubling time. J Urol 2008, 179:2181-2186

31. Bolla M, van Poppel H, Collette L, van Cangh P, Vekemans K, Da Pozzo L, de Reijke TM, Verbaeys Bosset JF, van Velthoven R, Marechal JM, Scalliet $P$, Haustermans K, Pierart M, European Organization for Research and Treatment of Cancer: Postoperative radiotherapy after radical prostatectomy: a randomised controlled trial (EORTC trial 22911). Lancet 2005, 366:572-578

32. Thompson IM Jr, Tangen CM, Paradelo J, Lucia MS, Miller G, Troyer D, Messing E, Forman J, Chin J, Swanson G, Canby-Hagino E, Crawford ED: Adjuvant radiotherapy for pathologically advanced prostate cancer: a randomized clinical trial. JAMA 2006, 296:2329-2335.

33. Thompson IM, Tangen CM, Paradelo J, Lucia MS, Miller G, Troyer D, Messing E, Forman J, Chin J, Swanson G, Canby-Hagino E, Crawford ED: Adjuvant radiotherapy for pathological T3NOMO prostate cancer significantly reduces risk of metastases and improves survival: long-term follwup of a randomized clinical trial. J Urol 2009, 181:956-962.

34. Jereczek-Fossa BA, Zerini D, Vavassori A, Fodor C, Santoro L, Minissale A, Cambria R, Cattani F, Garibaldi C, Serafini F, Matei VD, de Cobelli O, Orecchia R: Sooner or later? Outcome analysis of 431 prostate cancer patients treated with postoperative or salvage radiotherapy. Int I Radiat Oncol Biol Phys 2009, 74:115-125.

35. Spiotto MT, Hancock SL, King CR: Radiotherapy after prostatectomy: improved biochemical relapse-free survival with whole pelvic compared with prostate bed only for high-risk patients. Int I Radiat Oncol Biol Phys 2007, 69:54-61.

36. King CR, Spiotto MT: Improved outcomes with higher doses for salvage radiotherapy after prostatectomy. Int J Radiat Oncol Biol Phys 2008, 71:23-27.

37. King CR, Kapp DS: Radiotherapy after prostatectomy: is the evidence for dose escalation out there? Int I Radiat Oncol Biol Phys 2008, 71:346-350

38. Cozzarini C, Montorsi F, Fiorino C, Alongi F, Bolognesi A, Da Pozzo LF, Guazzoni G, Freschi M, Roscigno M, Scattoni V, Rigatti P, Di Muzio N: Need for high radiation dose (> or $=70 \mathrm{~Gy}$ ) in early postoperative irradiation after radical prostatectomy: a single-institution analysis of 334 high-risk, node-negative patients. Int J Radiat Oncol Biol Phys 2009, 74:966-974.

doi:10.1186/1748-717X-6-150

Cite this article as: Umezawa et al:: Impact of pathological tumor stage for salvage radiotherapy after radical prostatectomy in patients with prostate-specific antigen $<1.0 \mathrm{ng} / \mathrm{ml}$. Radiation Oncology 2011 6:150. 